\title{
Forkhead box P3 gene silencing inhibits the expression of chemokines and chemokine receptors associated with cell growth, migration, and apoptosis in hepatocellular carcinoma cells
}

\author{
XI OU ${ }^{1}$, GUANG-TAO ZHANG ${ }^{1}$, PEI-KAI TIAN ${ }^{2}$, JING-SEN CHEN $^{3}$, ZE-WEI LIN ${ }^{1}$, \\ YONG XIE ${ }^{1}$, AI-HONG WANG ${ }^{1}$, XIAO-PING LIU ${ }^{1}$ and JI-KUI LIU ${ }^{1}$ \\ ${ }^{1}$ Department of Hepatopancreatobiliary Surgery, Peking University Shenzhen Hospital, Shenzhen, Guangdong 518036; \\ ${ }^{2}$ Department of Hepatobiliary Surgery, Shenzhen University General Hospital, Shenzhen, Guangdong 518055; \\ ${ }^{3}$ Department of Breast Surgery, Shenzhen Maternity and Child Healthcare Hospital, Shenzhen, Guangdong 518028, P.R. China
}

Received July 4, 2018; Accepted May 2, 2019

DOI: $10.3892 / \mathrm{etm} .2019 .7658$

\begin{abstract}
The aberrant expression of forkhead box P3 (FOXP3) leads to the formation of malignant tumors. FOXP3 expression levels are also elevated in hepatocellular carcinoma (HCC). The aim of the present study was to investigate the effects of FOXP3 silencing on cell proliferation, migration, apoptosis and chemokine/chemokine receptor expression in the MHCC-97H HCC cell line. Three FOXP3 short hairpin (sh)RNA constructs were designed: Sh-FOXP3-1-pGreenPuro, sh-FOXP3-2-pGreenPuro, and sh-FOXP3-3-pGreenPuro. MHCC-97H cells were transfected with shRNA-FOXP3, and the mRNA and protein expression levels of $\mathrm{C}-\mathrm{X}-\mathrm{C}$ motif chemokine (CXC) ligand 12 (CXCL12), CXCL11, CXC receptor 4 (CXCR4) and CXCR7 were measured. Cell Counting Kit-8, terminal deoxynucleotidyl-transferase-mediated dUTP nick end labeling and Transwell assays were used to evaluate cell proliferation, apoptosis and migration, respectively. Of the three FOXP3 lentivirus carriers constructed, sh-FOXP3-1 significantly reduced FOXP3 expression levels and was chosen for further experiments. sh-FOXP3-1 inhibited cell proliferation, promoted apoptosis and inhibited cell migration compared with the negative control. The mRNA and protein expression levels of CXCL12, CXCL11, CXCR4 and CXCR7 were decreased significantly in response to FOXP3 silencing. FOXP3 silencing may therefore inhibit cell growth, induce apoptosis and inhibit migration in HCC cells, possibly by impairing the chemokine/chemokine receptor axes.
\end{abstract}

Correspondence to: Dr Xiao-Ping Liu or Dr Ji-Kui Liu, Department of Hepatopancreatobiliary Surgery, Peking University Shenzhen Hospital, 1120 Lian Hua Road, Shenzhen, Guangdong 518036, P.R. China

E-mail: ninliu11@163.com

E-mail: liu8929@126.com

Key words: forkhead box P3, hepatocellular carcinoma, chemokine/chemokine receptor axis, proliferation, apoptosis

\section{Introduction}

Hepatocellular carcinoma (HCC), which often develops as a result of hepatitis and liver cirrhosis, is one of the most common types of cancer worldwide. The majority of patients are diagnosed at an advanced stage, which results in poor survival rates (1). The mortality rate for patients with HCC is second only to that of lung cancer (2-4).

Forkhead box P3 (FOXP3) is a member of the transcription factor fork head protein family, and it serves a vital role in the generation of regulatory $\mathrm{T}$ cells (Tregs), which function largely in immunosuppression $(5,6)$. Aberrant FOXP3 expression leads to autoimmune disease and benign or malignant tumor formation. Previous studies regarding FOXP3 expression and function have been performed primarily in Tregs $(7,8)$. However, FOXP3 expression levels are also elevated in a number of tumor cell types, including HCC $(9,10)$. Additionally, the expression levels and cellular distribution of FOXP3 vary widely within the tumor and its microenvironment (11-13). By inhibiting the secretion of certain cytokines, such as transforming growth factor (TGF)- $\beta 1$, TGF- $\beta 2$, and interleukin-10, FOXP3 controls the growth of melanoma tumors (14). FOXP $^{+}$Tregs affect the development and progression of hepatocellular carcinoma $(15,16)$. FOXP3 may also act as a tumor suppressor in HCC by regulating the TGF- $\beta / \mathrm{Smad} 2 / 3$ signaling pathway (17).

Chemokines are a superfamily of small-molecules that bind to $\mathrm{G}$ protein-coupled receptors on the cell membrane and promote cell migration through the guanine nucleotide binding protein-mediated signaling cascade (18). Chemokines are grouped into $\mathrm{C}-\mathrm{X}-\mathrm{C}$ motif chemokine (CXC), $\mathrm{CX} 3 \mathrm{C}, \mathrm{CC}$ and $\mathrm{C}$ families based on their amino acid sequences. CXC ligand (CXCL) 12 is a CXC chemotactic factor that was originally identified in bone marrow stroma and termed stromal cell-derived factor-1 (SDF-1) (19). CXC receptor (CXCR) 4 belongs to the $\mathrm{G}$ protein-coupled receptor family and selectively binds CXCL12 $(18,19)$. The CXCL12/CXCR4 signaling pathway mediates proliferation, migration and migration in a variety of tumor cells, including lung (20) and gastric cancer (21), oral squamous cell carcinoma (22), and HCC $(23,24)$. CXCR7 was 
originally cloned from the cDNA library of the dog thyroid, and was considered to be an orphan receptor (25); CXCL12 and CXCL11 were later identified as ligands of CXCR7 (26). Of note, the CXCL12/CXCR7 axis also serves as a therapeutic target in the control of cell survival, cell adhesion and tumor development (27).

In a study of the molecular mechanisms of HCC progression, MHCC-97H cells are frequently used, as they share pathological and genetic characteristics of malignant liver tumors (28). In the present study, MHCC-97H cells were transfected with FOXP3-short hairpin (sh)RNAs to detect changes in cell proliferation, apoptosis and migration. In addition, the effect of FOXP3 silencing on chemokine/chemokine receptor expression was investigated.

\section{Materials and methods}

Cell culture. MHCC97-H cells were obtained from the Cell Bank of The Chinese Academy of Sciences and cultured in Dulbecco's modified Eagle's medium (DMEM; Gibco; Thermo Fisher Scientific, Inc.) supplemented with $10 \%$ fetal bovine serum (FBS; cat. no. 04-007-1A; Biological Industries) and $100 \mathrm{U} / \mathrm{ml}$ penicillin and $100 \mu \mathrm{g} / \mathrm{ml}$ streptomycin (Beijing Solarbio Science \& Technology Co., Ltd.) in $5 \% \mathrm{CO}_{2}$ at $37^{\circ} \mathrm{C}$. Cells were used for experiments at $60 \%$ confluence.

shRNA construction. The mRNA sequence of FOXP3 was obtained from the NCBI database (https://www.ncbi.nlm. nih.gov/gene/20371), and three shRNA sequences were designed accordingly (Table I). The sense strands included a BamHI restriction site and the antisense strands included an EcoRI restriction site. Double chains were formed and inserted into pGreenPuro vectors (cat. no. SI505A-1-SBI; System Biosciences). A total of three recombinant vectors were constructed: Sh-FOXP3-1-pGreenPuro, sh-FOXP3-2-pGreenPuro and sh-FOXP3-3. Single colonies were selected from plates harboring MHCC97-H cells with either sh-FOXP3-1-pGreenPuro, sh-FOXP3-2-pGreenPuro or sh-FOXP3-3-pGreenPuro. The vectors were prepared with a Plasmid Minipreparation kit (cat. no. KL060; Shanghai Kang Lang Biological technology Co., Ltd.) and detected using 2\% agarose gel electrophoresis with ethidium bromide staining.

The experiments were performed in three groups: A control group, a scrambled negative control (NC) group, and a sh-FOXP3-1-pGreenPuro group. Using the Lipofectamine ${ }^{\circledR}$ 3000 reagent (Invitrogen; Thermo Fisher Scientific, Inc.), DNA-liposome complexes were prepared at $4^{\circ} \mathrm{C}$ to a final volume of $1 \mu \mathrm{g} / \mu \mathrm{l}$ and added to MHCC97-H cells $(1 \mu \mathrm{g} / \mathrm{ml})$. Transfection was performed for $1 \mathrm{~h}$ at room temperature. Further experiments were performed 12, 24, 48 or $72 \mathrm{~h}$ post-transfection.

Reverse transcription quantitative-PCR (RT-qPCR). Total RNA was extracted using an Ultrapure RNA extraction kit (CoWin Biosciences Co., Ltd.), and RNA purity was assessed by measuring optical density (OD) at 280/260 $\mathrm{nm}$. Total RNA $(1 \mu \mathrm{g})$ was reverse transcribed into cDNA using an Avian Myeloblastosis Virus Reverse-Transcriptase kit (cat. no. KL041; Shanghai Kang Lang Biological technology Co., Ltd.). qPCR was performed in $25 \mu \mathrm{l}$ sample volumes including,
9.5 $\mu \mathrm{l}$ RNase-Free $\mathrm{dH}_{2} \mathrm{O}, 1 \mu \mathrm{l} \mathrm{cDNA} / \mathrm{DNA}, 2 \mu \mathrm{l}$ primers and $12.5 \mu \mathrm{l}$ UltraSYBR Mixture (cat. no. 00081405; CWBIO Corporation) with the following thermocycling conditions: 35 cycles of denaturation at $94^{\circ} \mathrm{C}$ for $45 \mathrm{sec}$, annealing at $59^{\circ} \mathrm{C}$ for $45 \mathrm{sec}$ and extension at $72^{\circ} \mathrm{C}$ for $60 \mathrm{sec}$. The $2^{-\Delta \Delta \mathrm{cq}}$ method was used for quantification (29). The primers used are presented in Table II.

Western blotting. Following transfection, MHCC97-H cells $\left(5 \times 10^{3} / \mathrm{ml}\right)$ were collected for western blot analysis. Protein was isolated using a protein isolation kit (ReadyPrep; GE Healthcare Life Sciences) and concentrations were quantified using a bicinchoninic acid assay (Thermo Fisher Scientific, Inc.) according to the manufacturer's protocol and $20 \mu \mathrm{g}$ protein/lane was separated using SDS-PAGE on $10 \%$ gel. The proteins were transferred to a nitrocellulose membrane. Non-specific protein binding was blocked with $5 \%$ non-fat milk at room temperature for $2 \mathrm{~h}$. The membranes were incubated with anti-GAPDH (1:1,000; cat. no. TA802519; OriGene Technologies, Inc.), anti-CXCR4 (1:500; cat. no. PA1237; Boster Biological Technology), anti-CXCR7 (1:500; cat. no. ab138509; Abcam), anti-CXCL11 (1:500; cat. no. abs139437; Absin Bioscience, Inc.) or anti-CXCL12 (1:500; cat. no. ab155090; Abcam) antibodies at $4^{\circ} \mathrm{C}$ overnight. The membranes were rinsed with $0.1 \%$ PBS $+0.1 \%$ Tween-20 and incubated with a horseradish peroxidase-labeled goat anti-rabbit immunoglobulin $\mathrm{G}(\mathrm{H}+\mathrm{L})$ secondary antibody (1:100; ZB-2301; OriGene Technologies, Inc.) at room temperature for $2 \mathrm{~h}$. The signal was detected using an Enhanced Chemiluminescence Detection kit (Thermo Fisher Scientific, Inc.) and ChemiDoc ${ }^{\mathrm{TM}}$ XRS system (Bio-Rad Laboratories, Inc.). Densitometry was performed using Quantity One software (version 1.4.6; Bio-Rad Laboratories, Inc.).

Cell Counting Kit (CCK)-8 assay. Following transfection for 12, 24, 48 and $72 \mathrm{~h}, 10 \mu \mathrm{l}$ of media containing CCK-8 (Gibco; Thermo Fisher Scientific, Inc.) were added to each well $\left(3 \times 10^{3} / \mathrm{ml}\right)$. An additional $4 \mathrm{~h}$ of incubation at $37^{\circ} \mathrm{C}$ was performed following each transfection at 12, 24, 48 and $72 \mathrm{~h}$. OD was detected using a microplate reader (Thermo Fisher Scientific, Inc.) at $490 \mathrm{~nm}$, and cell viability was determined based on the OD values.

Terminal deoxynucleotidyl-transferase-mediated dUTP nick end labeling (TUNEL). MHCC97-H cells were fixed in $4 \%$ paraformaldehyde for $30 \mathrm{~min}$ at room temperature and incubated with PBS $+0.1 \%$ Tween-20 containing $0.3 \%$ Triton $\mathrm{X}-100$ for $5 \mathrm{~min}$ at room temperature. TUNEL solution was added to each well and the cells were incubated at $37^{\circ} \mathrm{C}$ for $60 \mathrm{~min}$. Nuclei were stained with DAPI $(5 \mathrm{mg} / \mathrm{ml})$ for $3 \mathrm{~min}$ at room temperature, following which slides were covered with mounting medium (cat. no. P0126; Beyotime Institute of Biotechnology). Images of the cells were captured using fluorescence microscopy at 5 fields of view.

Transwell assay. Following transfection, 3x103 $\mathrm{MHCC} 97-\mathrm{H}$ cells were seeded in the upper chamber of Transwell plates (Hyclone; GE Healthcare Life Sciences) with serum-free DMEM. The lower chamber contained DMEM with $10 \%$ FBS. At 48 h, the cells in the lower chamber were fixed with 
Table I. Sequences of FOXP3 shRNAs.

\begin{tabular}{ll} 
Primer & \\
\hline sh-FOXP3-F1 & Sequence $\left(5^{\prime} \rightarrow 3^{\prime}\right)$ \\
sh-FOXP3-R1 & AATTCGCCACATTTCATGCACCAGCTCTCGAGAGCTGGTGCATGAAATGTGGCG \\
sh-FOXP3-F2 & GATCCGCACTGACCAAGGCTTCATCTCTCGAGAGATGAAGCCTTGGTCAGTGCTTTTTG \\
sh-FOXP3-R2 & AATTCGCACTGACCAAGGCTTCATCTCTCGAGAGATGAAGCCTTGGTCAGTGCG \\
sh-FOXP3-F3 & GATCCGCATGTTTGCCTTCTTCAGAACTCGAGTTCTGAAGAAGGCAAACATGCTTTTTG \\
sh-FOXP3-R3 & AATTCGCATGTTTGCCTTCTTCAGAACTCGAGTTCTGAAGAAGGCAAACATGCG \\
sh-NC-F & GATCCTTCTCCGAACGTGTCACGTAATTCAAGAGATTACGTGACACGTTCGGAGAATTTTTTG \\
sh-NC-R & AATTCAAAAAATTCTCCGAACGTGTCACGTAATCTCTTGAATTACGTGACACGTTCGGAGAAG
\end{tabular}

FOXP3, forkhead box P3; sh, short hairpin RNA. NC, Scrambled control; F, forward; R, reverse.

Table II. Primer sequences used for reverse transcriptionquantitative PCR.

\begin{tabular}{ll}
\hline Gene & \multicolumn{1}{c}{ Sequence $\left(5^{\prime} \rightarrow 3^{\prime}\right)$} \\
\hline FOXP3 & F: GTGGCATCATCCGACAAGG \\
& R: AGCGTGGCGTAGGTGAAAG \\
FXCR4 & F: TAAAATCTTCCTGCCCACC \\
& R: CGCCAACATAGACCACCTT \\
CXCR7 & F: CTCTTCGGCAGCATTTCT \\
& R: CGTGACGGTCTTCAGGTAGTA \\
CXCL11 & F: ATGTTCAAAAGAGGACGCTG \\
& R: GTTACTTGGGTACATTATGGAGG \\
CXCL12 & F: ACTCCAAACTGTGCCCTTCA \\
& R: CCACTTTAGCTTCGGGTCAAT \\
GAPDH & F: GAAGGTCGGAGTCAACGGAT \\
& R: CCTGGAAGATGGTGATGGG
\end{tabular}

FOXP3, forkhead box P3; CXCR, C-X-C motif chemokine receptor; CXCL, C-X-C motif chemokine ligand; F, forward; R, reverse.

4\% paraformaldehyde at room temperature for $30 \mathrm{~min}$ and stained with $1 \%$ crystal violet (Beijing Solarbio Science \& Technology Co., Ltd.) for $5 \mathrm{~min}$ at room temperature. Images were captured using a light microscope (Magnification, $\mathrm{x} 200$ ). At least five random fields of view in each image were counted.

Statistical analysis. Data are presented as the mean \pm standard deviation with six independent replicates. Statistical analyses were performed using SPSS software (version 17; SPSS, Inc.) and data were analyzed by one-way analysis of variance followed by a Bonferroni post-hoc test. $\mathrm{P}<0.05$ was considered to indicate a statistically significant difference.

\section{Results}

Characterization of FOXP3 shRNAs. Vectors were detected by $2 \%$ agarose gel electrophoresis (Fig. 1). The band sizes reflected the predicted sizes of the constructs.

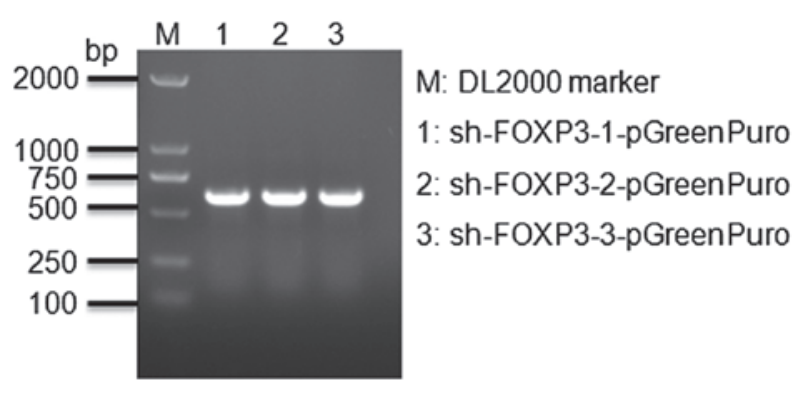

Figure 1. shRNA sequences used to silence FOXP3 expression. The bands sizes were similar to the predicted sizes of the shRNA constructs.

Transfection with either one of the three sh-FOXP3 sequences reduced FOXP3 mRNA and protein expression levels in MHCC97-H cells (Fig. 2). The sh-FOXP3-1 shRNA exhibited the strongest reduction of FOXP3 mRNA and protein expression levels. Therefore, sh-FOXP3-1 was selected for further experiments.

FOXP3 silencing inhibits cell proliferation in $M H C C 97-H$ cells. The OD of MHCC-97H cells treated with sh-FOXP3-1 was significantly lower compared with the negative control group following transfection for 12, 24, 48 and 72 h (Fig. 3), which suggested that FOXP3 silencing may inhibit cell proliferation in MHCC97-H cells. The OD values at $72 \mathrm{~h}$ were: Control, 0.96; NC, 0.96; sh-FOXP3-1, 0.42 [F(2, 15)=20.5; overall comparison between the 3 groups, $\mathrm{P}<0.0001]$.

FOXP3 silencing promotes apoptosis in MHCC97-H cells. The results of the TUNEL assay revealed that the number of apoptotic cells following treatment with sh-FOXP3-1 was significantly higher compared with that in the negative control group (Fig. 4). The percentages of apoptotic cells in each group were: Control, 4.0\%; NC, 11.0\%; sh-FOXP3-1, 26.6\% $[\mathrm{F}(2,15)=20.5 ; \mathrm{P}<0.05)$. These data suggested that FOXP3 silencing may promote apoptosis in MHCC97-H cells.

FOXP3 silencing inhibits the migration of MHCC97-H cells. The rate of migration of cells transfected with sh-FOXP3-1 was significantly lower compared with the negative control group (Fig. 5). The number of invasive cells was: Control, 
A

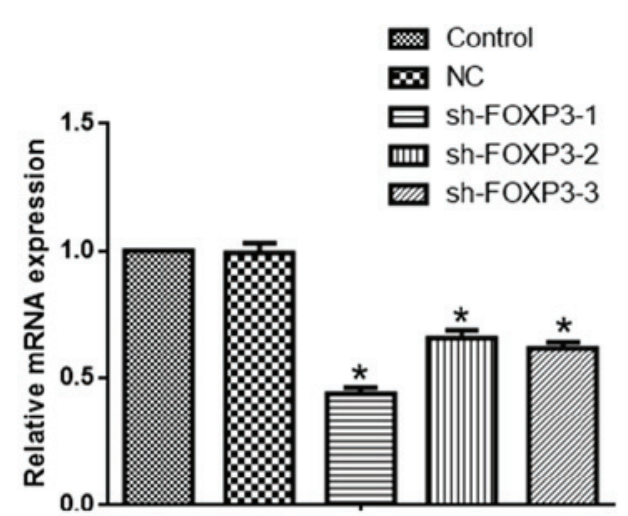

B
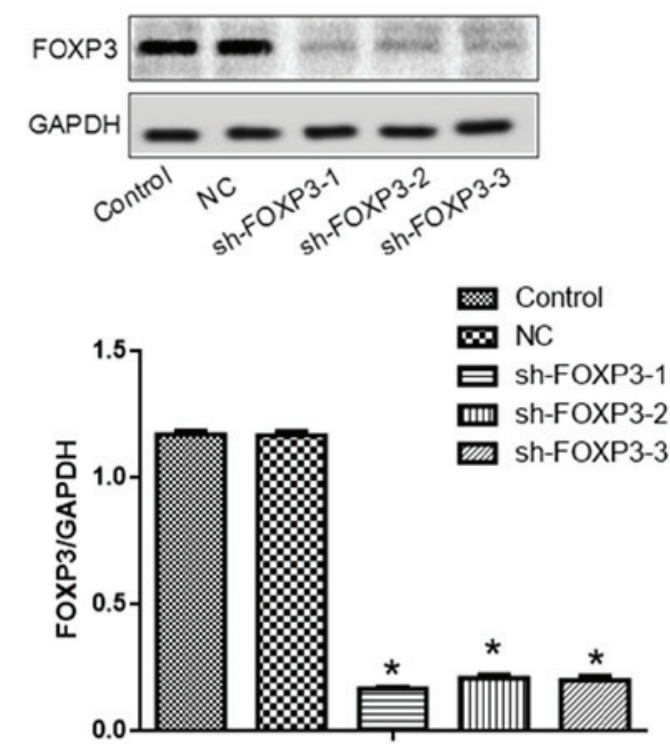

Figure 2. FOXP3 shRNAs inhibit FOXP3 mRNA and protein expression. (A) mRNA expression levels of FOXP3 following transfection with sh-FOXP3. (B) Representative blots and quantified data of protein expression levels of FOXP3 following transfection with sh-FOXP3. All three sh-FOXP3 sequences reduced FOXP3 protein and mRNA expression in MHCC-97H cells. ${ }^{*} \mathrm{P}<0.05$ vs. NC. NC, negative control; FOXP3, forkhead box P3; sh-FOXP3, short hairpin RNA targeting FOXP3.

936; NC, 923; sh-FOXP3-1, $96[\mathrm{~F}(2,15)=473, \mathrm{P}<0.05)$. These data suggest that FOXP3 silencing may inhibit migration in MHCC97-H cells.

FOXP3 silencing reduces the expression of chemokines and their receptors in MHCC97-H cells. The mRNA expression levels of CXCL12, CXCL11, CXCR4 and CXCR7 were reduced in cells transfected with sh-FOXP3-1 compared with the negative control group $(\mathrm{P}<0.05$; Fig. 6). Similarly, the protein levels of CXCL12, CXCL11, CXCR4, and CXCR7 were reduced in cells treated with sh-FOXP3-1 compared with the NC group $(\mathrm{P}<0.05$; Fig. 7).

\section{Discussion}

HCC is primarily treated with radiotherapy and liver transplantation; however, the rates of recurrence are $\sim 54 \%$ at a median time of 22 months from primary resection $(30,31)$. FOXP3, a nuclear transcription factor linked to the $\mathrm{X}$

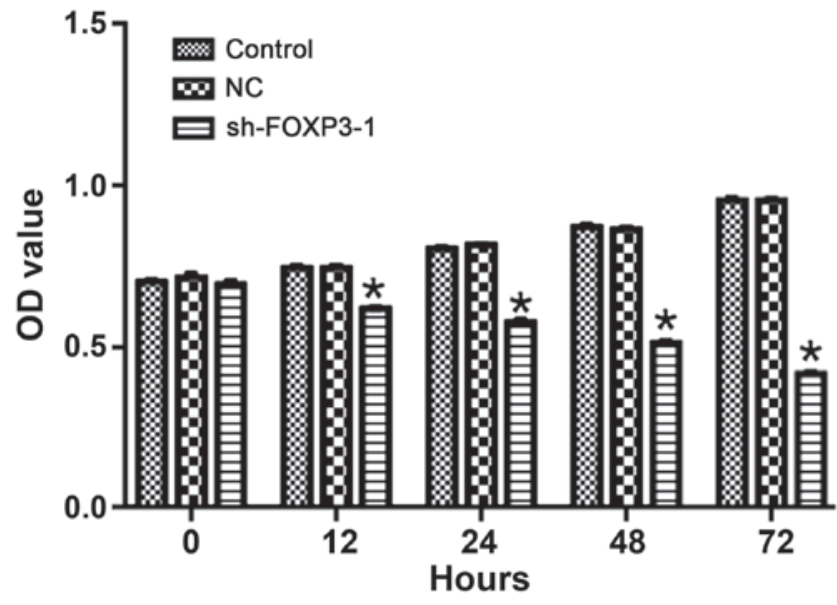

Figure 3. FOXP3 silencing inhibits cell proliferation in hepatocellular carcinoma cells. The OD values in cells treated with sh-FOXP3-1 were lower compared with the control group following transfection for 12, 24, 48 and 72 h. "P<0.05 vs. NC. OD, optical density; NC, negative control; FOXP3, forkhead box P3; sh-FOXP3-1, short hairpin RNA targeting FOXP3, sequence 1.
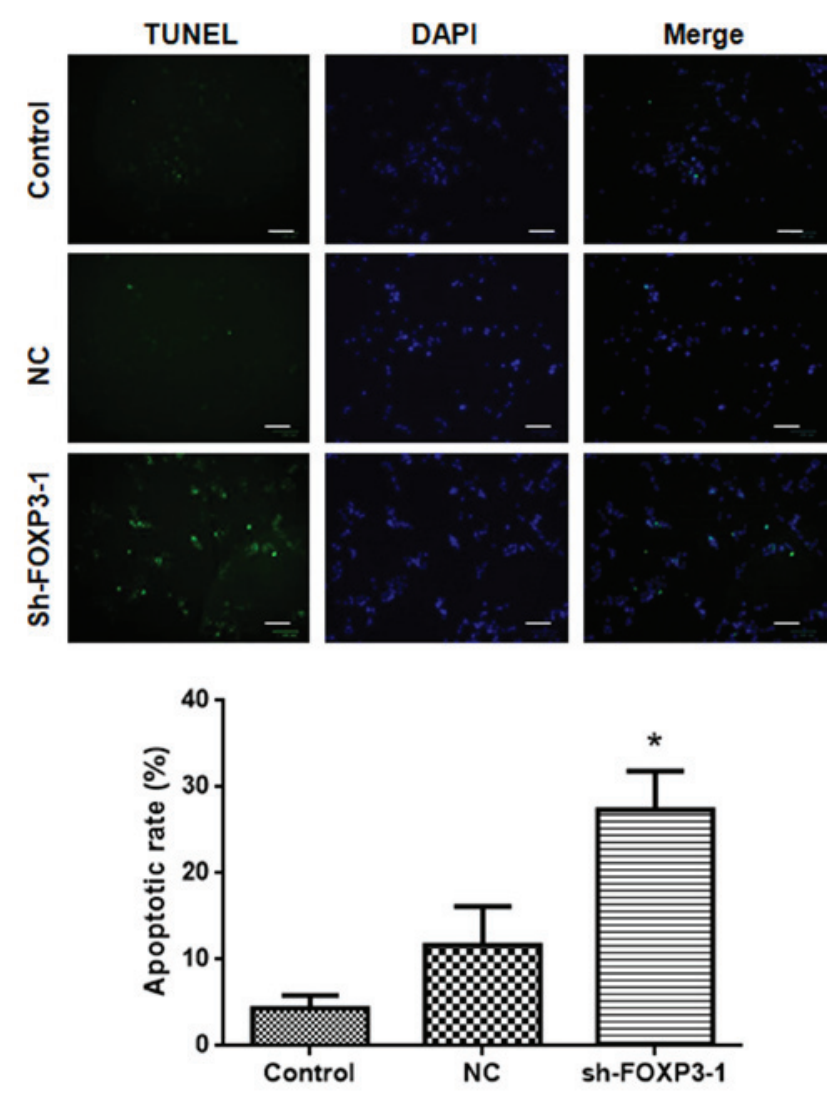

Figure 4. FOXP3 silencing induces apoptosis in MHCC-97H cells. The percentage of apoptotic cells in response to sh-FOXP3-1 was significantly higher compared with the control group. " $\mathrm{P}<0.05$ vs. NC. Scale bar, $100 \mu \mathrm{m}$. NC, negative control; FOXP3, forkhead box P3; sh-FOXP3-1, short hairpin RNA targeting FOXP3, sequence 1.

chromosome that belongs to the forkhead/winged helix transcription factor family, was originally identified by cloning the Scurfin gene. The head domain of FOXP3 binds to DNA-specific loci to regulate the activation and expression of its target genes $(5,6)$. FOXP3 consists of 431 amino acids 


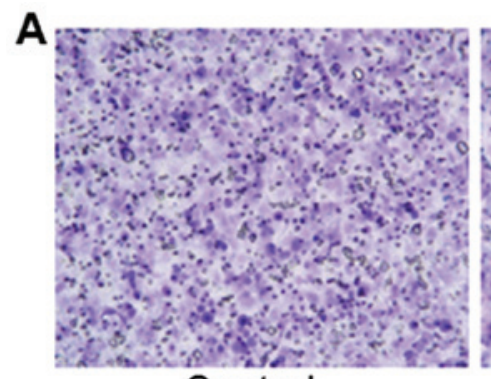

Control

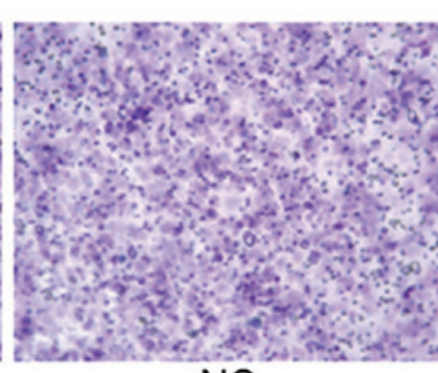

NC

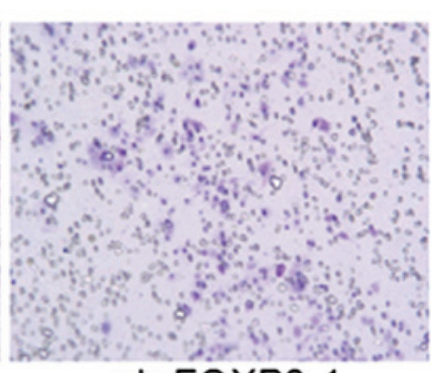

sh-FOXP3-1

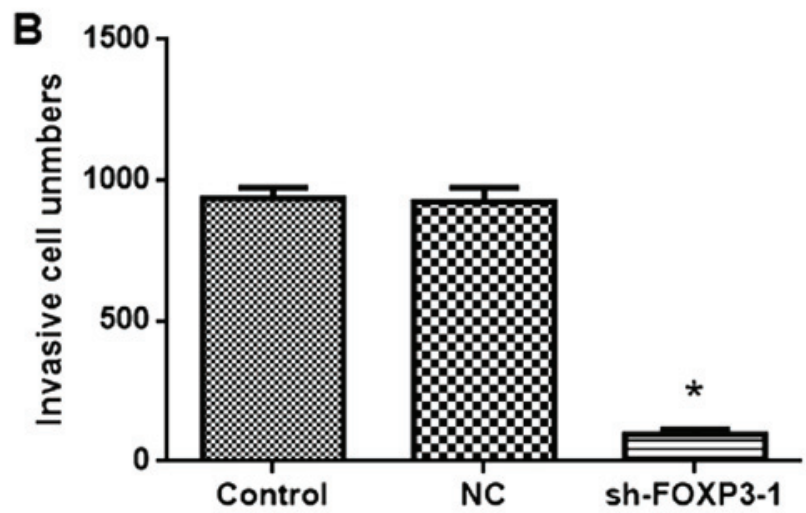

Figure 5. FOXP3 silencing inhibits migration in MHCC-97H cells. (A) Representative images of invasive cells. Magnification, x100. (B) The number of invasive cells in response to sh-FOXP3-1 was significantly lower compared with the control group. ${ }^{*} \mathrm{P}<0.05$ vs. NC. NC, negative control; FOXP3, forkhead box P3; sh-FOXP3-1, short hairpin RNA targeting FOXP3, sequence 1.

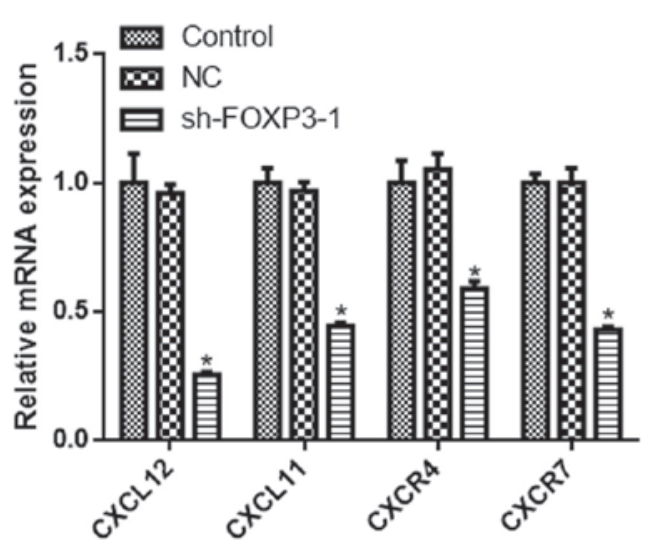

Figure 6. FOXP3 silencing reduces the mRNA expression levels of chemokines and their receptors in hepatocellular carcinoma cells. The mRNA expression levels of CXCL12, CXCL11, CXCR4, and CXCR7 were reduced in cells treated with sh-FOXP3-1 compared with the control group. ${ }^{\text {}} \mathrm{P}<0.05$ vs. NC. NC, negative control; FOXP3, forkhead box P3; sh-FOXP3-1, short hairpin RNA targeting FOXP3, sequence 1; CXCL, C-X-C motif chemokine ligand; CXCR, C-X-C motif chemokine receptor.

and its functional structure includes a forkhead DNA binding zone at the $\mathrm{C}$ terminal, a $\mathrm{C} 2 \mathrm{H} 2$ zinc finger structure at the $\mathrm{N}$ terminal, and a leucine zipper sequence (32). In humans, FOXP3 is primarily responsible for the immunosuppressive function of Tregs, and is frequently used as a Treg-specific marker. It serves an important role in regulating the growth and function of $\mathrm{CD} 4{ }^{+} \mathrm{CD} 25^{+}$Tregs, as well as maintaining immune tolerance and the stability of the immune responses by inducing the development of $\mathrm{CD} 4{ }^{+} \mathrm{CD} 25^{+}$Tregs, controlling
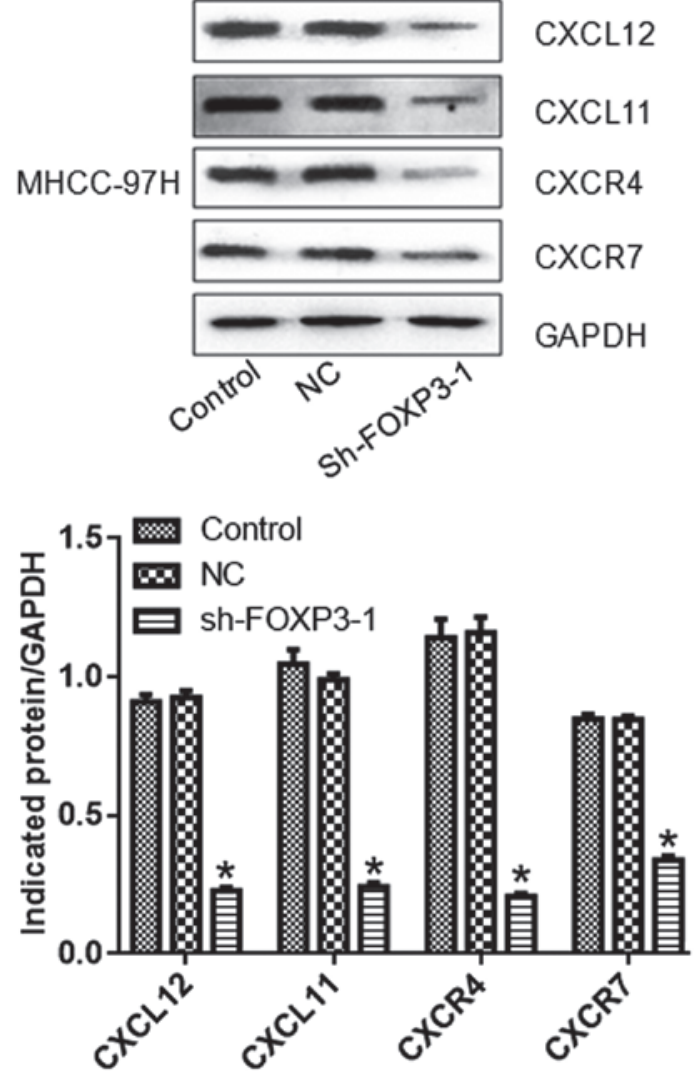

Figure 7. FOXP3 silencing reduces the expression of chemokines and chemokine receptors at the protein level in hepatocellular carcinoma cells. The expression of CXCL12, CXCL11, CXCR4 and CXCR7 at the protein level was reduced in the sh-FOXP3-1 group compared with respective controls. ${ }^{*} \mathrm{P}<0.05$ vs. NC. NC, negative control; FOXP3, forkhead box P3; sh-FOXP3-1, short hairpin RNA targeting FOXP3, sequence 1; CXCL, $\mathrm{C}-\mathrm{X}-\mathrm{C}$ motif chemokine ligand; $\mathrm{CXCR}, \mathrm{C}-\mathrm{X}-\mathrm{C}$ motif chemokine receptor. 
the production of $\mathrm{CD}^{+}$Tregs and determining Treg inhibitory function (33).

FOXP3 is expressed in various types of tumor cells (34). The expression pattern of FOXP3, including expression levels, subcellular localization and subtypes, in tumor cells is different compared with that in normal cells or Tregs (34). Cunha et al (35) highlighted the complexity of FOXP3 expression in tumor cells, as well as the diverse roles it serves in tumor progression. Wang et al (36) previously characterized $10 \mathrm{HCC}$ cell lines with high expression levels of FOXP3. Niu et al (37) demonstrated that melanoma cells underwent immune escape by expressing FOXP3. Silencing of FOXP3 by FOXP3-siRNA has been demonstrated to mitigate the expression of $\mathrm{B} 7-\mathrm{H} 1$ and $\mathrm{TGF}-\beta$, whereas FOXP3 overexpression increased the expression of these molecules (38). Co-culturing FOXP $3^{+}$melanoma cells with $\mathrm{CD}^{+}{ }^{+} \mathrm{CD} 25^{-}$Tregs strongly inhibited the proliferation of $\mathrm{T}$ cells, which was partially reversed by the specific silencing of FOXP3 and effectively enhanced by FOXP3 overexpression (39). Therefore, FOXP3 not only serves an important role in Treg function, but may also modulate tumor cell behavior directly.

In the present study, three shRNAs were constructed to silence FOXP3 expression in HCC cells; sh-FOXP3-1 exhibited the strongest silencing effects in an HCC cell line. The results indicated that silencing of FOXP3 expression may inhibit the proliferation of HCC cells. Apoptosis was also promoted in response to sh-FOXP3-1, whereas migration was inhibited. Collectively, these data demonstrate that the silencing of FOXP3 in tumor cells may regulate $\mathrm{HCC}$ proliferation, migration and apoptosis.

Compared with CXCL12/CXCR4, the CXCL12/CXCR7 signaling has a more pronounced effect on HCC progression (40). Downregulation of CXCR7 results in the reduction of HCC cell proliferation, as well as the inhibition of lung metastasis (41). Sutton et al (42) demonstrated that CXCL12 stimulates the proliferation, migration and migration of HCC cells, and that the combination of CXCL12 and CXCR4 induces the aggregation and redistribution of cytoskeletal proteins, which enhances the rates of migration and migration. In addition, CXCR7 binds CXCL11 and CXCL12 with high affinity, thus serving important roles in the progression of HCC (43). In the present study, the mRNA and protein levels of CXCL12, CXCL11, CXCR4 and CXCR7 were significantly decreased in MHCC97-H cells treated with sh-FOXP3-1 compared with the control groups. These results suggested that FOXP3 may serve an important role in the growth and metastasis of HCC, potentially through the chemokine/chemokine receptor axis. This may be one of the primary mechanisms underlying the FOXP3 silencing-mediated regulation of tumor growth, inhibition of oncogene transcription and induction of tumor suppressor gene expression.

FOXP3 binds to the transcription sites of the CXCR4 and CXCR7 genes (44);CXCR4 andCXCR7 are associated with tumor migration and metastasis (24). Overbeck-Zubrzycka et al (45) have demonstrated that FOXP3 affects tumor migration and metastasis by modulating the CXCL12/CXCR4 pathway. In the present study, FOXP3 silencing prevented tumor migration potentially through inhibition of CXCR7. Pre-clinical studies have also demonstrated that CXCL12/CXCR4 and
CXCL12/CXCR7 inhibitors display potent anti-tumor properties (46), which suggests that chemokines and their receptors represent new potential targets for cancer therapy.

In the present study, FOXP3 silencing inhibited the expression of chemokines and chemokine receptors associated with cell proliferation, migration and apoptosis in an HCC cell line. However, a direct link between tumor progression and the activities of chemokines and chemokine receptors in response to FOXP3 silencing has not been established. Future studies will focus on detecting the downstream molecules of chemokines and their receptors that are regulated by FOXP3.

In conclusion, FOXP3 silencing may inhibit the expression of chemokines and chemokine receptors, including CXCL12/CXCR4, CXCL12/CXCR7 and CXCL11/CXCR7, and may be associated with the inhibition of cell proliferation and migration, as well as the induction of apoptosis. The inhibition of chemokine and chemokine receptor expression may represent an important mechanism underlying the effects of FOXP3 silencing in HCC cells.

\section{Acknowledgements}

Not applicable.

\section{Funding}

The present study was supported by the Science and Technology Development Fund Project of Shenzhen (grant nos. JCYJ20150403091443302 and JCYJ20160428164539088), the Sanming Project of Medicine in Shenzhen (grant no. SZSM201612021), the Science and Technology Developing Project of Guangdong Province (grant no. 2017B090904010) and Research Foundation of Peking University Shenzhen Hospital (grant no. JCYJ2018002).

\section{Availability of data and materials}

The datasets used and/or analyzed during the present study are available from the corresponding author on reasonable request.

\section{Authors' contributions}

$\mathrm{XO}, \mathrm{XL}$ and JL conceived and designed the study. XO, GZ, PT, JC, ZL, YX, AW and XL performed the experiments. XO, $\mathrm{XL}$ and JL wrote the paper. All authors read and approved the manuscript.

\section{Ethics approval and consent to participate}

Not applicable.

\section{Patient consent for publication}

Not applicable.

\section{Competing interests}

The authors declare that they have no competing interests. 


\section{References}

1. Singh AK, Kumar R and Pandey AK: Hepatocellular carcinoma: Causes, mechanism of progression and biomarkers. Curr Chem Genom Transl Med 12: 9-26, 2018

2. Glantzounis GK, Kyrochristos ID, Ziogas DE, Lykoudis EG and Roukos DH: Novel translational therapeutic strategy by sequencing primary liver cancer genomes. Future Oncol 13 : 1049-1052, 2017.

3. Yang B, Petrick JL, Kelly SP, Graubard BI, Freedman ND and McGlynn KA: Adiposity across the adult life course and incidence of primary liver cancer: The NIH-AARP cohort. Int J Cancer 141: 271-278, 2017.

4. Lan L, Zhao F, Cai Y, Wu RX and Meng Q: Epidemiological analysis on mortality of cancer in China, 2015. Zhonghua Liu Xing Bing Xue Za Zhi 39: 32-34, 2018 (In Chinese).

5. Sakaguchi S, Yamaguchi T, Nomura T and Ono M: Regulatory $T$ cells and immune tolerance. Cell 133: 775-787, 2008.

6. Bennett CL, Christie J, Ramsdell F, Brunkow ME, Ferguson PJ, Whitesell L, Kelly TE, Saulsbury FT, Chance PF and Ochs HD The immune dysregulation, polyendocrinopathy, enteropathy, $\mathrm{X}$-linked syndrome (IPEX) is caused by mutations of FOXP3. Nat Genet 27: 20-21,2001.

7. Malik S and Awasthi A: Transcriptional control of Th9 cells: Role of foxo1 in interleukin-9 induction. Front Immunol 9: 995, 2018.

8. Wada M, Tsuchikawa T, Kyogoku N, Abiko T, Miyauchi K, Takeuchi S, Kuwatani T, Shichinohe T, Miyahara Y, Kageyama S, et al: Clinical implications of $\mathrm{CD} 4^{+} \mathrm{CD} 25^{+} \mathrm{Foxp}^{+}$Regulatory $\mathrm{T}$ cell frequencies after CHPMAGE-A4 cancer vaccination. Anticancer Res 38: 1435-1444, 2018.

9. Lin SZ, Chen KJ, Xu ZY, Chen H, Zhou L, Xie HY and Zheng SS: Prediction of recurrence and survival in hepatocellular carcinoma based on two cox models mainly determined by FoxP3+ regulatory T cells. Cancer Prev Res (Phila) 6: 594-602, 2013

10. Triulzi T, Tagliabue E, Balsari A and Casalini P: FOXP3 expression in tumor cells and implications for cancer progression. J Cell Physiol 228: 30-35, 2013.

11. McInnes N, Sadlon TJ, Brown CY, Pederson S, Beyer M, Schultze JL, McColl S, Goodall GJ and Barry SC: FOXP3 and FOXP3-regulated microRNAs suppress SATB1 in breast cancer cells. Oncogene 31: 1045-1054, 2012.

12. Merlo A, Casalini P, Carcangiu ML, Malventano C, Triulzi T, Mènard S, Tagliabue E and Balsari A: FOXP3 expression and overall survival in breast cancer. J Clin Oncol 27: 1746-1752, 2009.

13. Ebert LM, Tan BS, Browning J, Svobodova S, Russell SE, Kirkpatrick N, Gedye C, Moss D, Ng SP, MacGregor D, et al: The regulatory $\mathrm{T}$ cell-associated transcription factor FoxP3 is expressed by tumor cells. Cancer Res 68: 3001-3009, 2008

14. Chen DJ, Li XS, Zhao H, Shi XL, Zhang HH, Fan ZY, Yao YM and DU N: Inhibitory effect of lentiviral-mediated RNA on the expression of Foxp3 protein in melanoma cells. Xi Bao Yu Fen Zi Mian Yi Xue Za Zhi 28: 337-339, 2012 (In Chinese).

15. Kobayashi N, Hiraoka N, Yamagami W, Ojima H, Kanai Y, Kosuge T, Nakajima A and Hirohashi S: FOXP3+ regulatory T cells affect the development and progression of hepatocarcinogenesis. Clin Cancer Res 13: 902-911, 2007.

16. Wang WH, Jiang CL, Yan W, Zhang YH, Yang JT, Zhang C, Yan B, Zhang W, Han W, Wang JZ and Zhang YQ: FOXP3 expression and clinical characteristics of hepatocellular carcinoma. World J Gastroenterol 16: 5502-5509, 2010

17. Shi JY, Ma LJ, Zhang JW, Duan M, Ding ZB, Yang LX, Cao Y, Zhou J, Fan J, Zhang X, et al: FOXP3 Is a HCC suppressor gene and Acts through regulating the TGF- $\beta / \mathrm{Smad} 2 / 3$ signaling pathway. BMC Cancer 17: 648, 2017.

18. Nagasawa T: CXC chemokine ligand 12 (CXCL12) and its receptor CXCR4. J Mol Med 92: 433-439, 2014.

19. Liu X, Dai LI and Zhou R: Association between preeclampsia and the CXC chemokine family (Review). Exp Ther Med 9: $1572-1576,2015$.

20. Zhou XM, He L, Hou G, Jiang B, Wang YH and Zhao L: Clinicopathological significance of CXCR4 in non-small cell lung cancer. Drug Des Devel Ther 9: 1349-1358, 2015.

21. Izumi D, Ishimoto $T$, Miyake $K$, Sugihara $H$, Eto $K$, Sawayama H, Yasuda T, Kiyozumi Y, Kaida T, Kurashige J, et al: CXCL12/CXCR4 activation by cancer-associated fibroblasts promotes integrin $\beta 1$ clustering and invasiveness in gastric cancer. Int J Cancer 138: 1207-1219, 2016.
22. Rave-Frank M, Tehrany N, Kitz J, Leu M, Weber HE, Burfeind P, Schliephake H, Canis M, Beissbarth T, Reichardt HM and Wolff HA: Prognostic value of CXCL12 and CXCR4 in inoperable head and neck squamous cell carcinoma. Strahlenther Onkol 192: 47-54, 2016

23. Fontanella R, Pelagalli A, Nardelli A, D'Alterio C, Ieranò C, Cerchia L, Lucarelli E, Scala S and Zannetti A: A novel antagonist of CXCR4 prevents bone marrow-derived mesenchymal stem cell-mediated osteosarcoma and hepatocellular carcinoma cell migration and invasion. Cancer Lett 370: 100-107, 2016

24. Shi JY, Yang LX, Wang ZC, Wang LY, Zhou J, Wang XY, Shi GM, Ding ZB, Ke AW, Dai Z, et al: CC chemokine receptor-like 1 functions as a tumour suppressor by impairing CCR7-related chemotaxis in hepatocellular carcinoma. J Pathol 235: 546-558, 2015.

25. Hao M, Zheng J, Hou K, Wang J, Chen X, Lu X, Bo J, Xu C, Shen K and Wang J: Role of chemokine receptor CXCR7 in bladder cancer progression. Biochem Pharmacol 84: 204-214, 2012.

26. Benredjem B, Girard M, Rhainds D, St-Onge G and Heveker N: Mutational analysis of atypical chemokine receptor 3 (ACKR3/CXCR7) interaction with its chemokine ligands CXCL11 and CXCL12. J Biol Chem 292: 31-42, 2017.

27. Burns JM, Summers BC, Wang Y, Melikian A, Berahovich R, Miao Z, Penfold ME, Sunshine MJ, Littman DR, Kuo CJ, et al: A novel chemokine receptor for SDF-1 and I-TAC involved in cell survival, cell adhesion, and tumor development. J Exp Med 203: 2201-2213, 2006

28. Li Y, Lu Z, Liang Z, Ji D, Zhang P, Liu Q, Zheng X and Yao Y: Metastasis-associated in colon cancer-1 is associated with poor prognosis in hepatocellular carcinoma, partly by promoting proliferation through enhanced glucose metabolism. Mol Med Rep 12: 426-434, 2015.

29. Livak KJ and Schmittgen TD: Analysis of relative gene expression data using real-time quantitative PCR and the 2(-Delta Delta C(T)) method. Methods 25: 402-408, 2001

30. Wiedmann MW and Mossner J: Molecular targeted therapy of hepatocellular carcinoma-results of the first clinical studies. Curr Cancer Drug Targets 11: 714-733, 2011.

31. Tabrizian P, Jibara G, Shrager B, Schwartz M and Roayaie S: Recurrence of hepatocellular cancer after resection: Patterns, treatments, and prognosis. Ann Surg 261: 947-955, 2015.

32. Lopes JE, Torgerson TR, Schubert LA, Anover SD, Ocheltree EL, Ochs HD and Ziegler SF: Analysis of FOXP3 reveals multiple domains required for its function as a transcriptional repressor. J Immunol 177: 3133-3142, 2006.

33. Rudensky AY: Regulatory T cells and Foxp3. Immunol Rev 241: 260-268, 2011

34. Grimmig T,Kim M,GermerCT, Gasser Mand Waaga-Gasser AM: The role of FOXP3 in disease progression in colorectal cancer patients. Oncoimmunology 2: e24521, 2013.

35. Cunha LL, Morari EC, Nonogaki S, Soares FA, Vassallo J and Ward LS: Foxp3 expression is associated with aggressiveness in differentiated thyroid carcinomas. Clinics 67: 483-488, 2012.

36. Wang L, Mei M, Sun X, et al: Expression and significance of Foxp3 in hepatocellular carcinoma. Shandong Med J 48: 8-11, 2010 (In Chinese).

37. Niu J, Jiang C, Li C, Liu L, Li K, Jian Z and Gao T: Foxp3 expression in melanoma cells as a possible mechanism of resistance to immune destruction. Cancer Immunol Immunother 60: 1109-1118, 2011.

38. Geng Y, Wang H, Lu C, Li Q, Xu B, Jiang J and Wu C: Expression of costimulatory molecules B7-H1, B7-H4 and Foxp3+ Tregs in gastric cancer and its clinical significance. Int J Clin Oncol 20: 273-281, 2015.

39. Fu S, Zhang N, Yopp AC, Chen D, Mao M, Chen D, Zhang H, Ding Y and Bromberg JS: TGF-beta induces Foxp3 + T-regulatory cells from CD4+CD25-precursors. Am J Transplant 4: 1614-1627, 2004.

40. Zheng K, Li HY, Su XL, Wang XY, Tian T, Li F and Ren GS: Chemokine receptor CXCR7 regulates the invasion, angiogenesis and tumor growth of human hepatocellular carcinoma cells. J Exp Clin Cancer Res 29: 31, 2010.

41. Xue TC, Chen RX, Han D, Chen J, Xue Q, Gao DM, Sun RX, Tang ZY and Ye SL: Down-regulation of CXCR7 inhibits the growth and lung metastasis of human hepatocellular carcinoma cells with highly metastatic potential. Exp Ther Med 3: 117-123, 2012 . 
42. Sutton A, Friand V, Brulé-Donneger S, Chaigneau T, Ziol M, Sainte-Catherine O, Poiré A, Saffar L, Kraemer M, Vassy J, et al: Stromal cell-derived factor-1/chemokine (C-X-C motif) ligand 12 stimulates human hepatoma cell growth, migration, and invasion. Mol Cancer Res 5: 21-33, 2007.

43. Monnier J, Boissan M, L'Helgoualc'h A, Lacombe ML, Turlin B, Zucman-Rossi J, Théret N, Piquet-Pellorce C and Samson M: CXCR7 is up-regulated in human and murine hepatocellular carcinoma and is specifically expressed by endothelial cells. Eur J Cancer 48: 138-148, 2012.

44. Zheng Y and Rudensky AY: Foxp3 in control of the regulatory T cell lineage. Nat Immunol 8: 457-462, 2007.

45. Overbeck-Zubrzycka D, Ali S, Kirby J and Lennard T: FOXP3 transcription factor regulates metastatic spread of breast cancer via control of expression of CXCR4 chemokine receptor. Br J Surg 98: 84, 2011.
46. Duda DG, Kozin SV, Kirkpatrick ND, Xu L, Fukumura D and Jain RK: CXCL12 (SDF1alpha)-CXCR4/CXCR7 pathway inhibition: An emerging sensitizer for anticancer therapies? Clin Cancer Res 17: 2074-2080, 2011.

This work is licensed under a Creative Commons Attribution-NonCommercial-NoDerivatives 4.0 International (CC BY-NC-ND 4.0) License. 